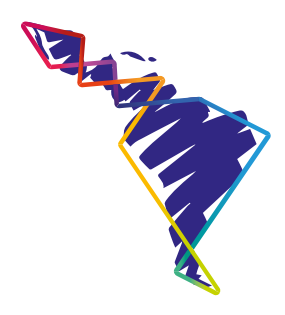

\title{
Artistas en el exilio: Teatro del Ángel y Surco en Costa Rica, 1973-1988
}

\author{
Artists in Exile: Teatro del Ángel \\ and Teatro Surco in Costa Rica, \\ 1973-1988.
}

\author{
Artistas no exílio: Teatro del Ángel e \\ Teatro Surco, na Costa Rica, 1973-1988.
}

\section{Diana Rojas Mejías'}

\section{Resumen}

Este trabajo estudia dos grupos de teatro chileno radicados en Costa Rica a raíz de la dictadura de Augusto Pinochet: Teatro del Ángel y Surco. Para llevarlo a cabo, se reconstruyen breves biografías de estos artistas en su país de origen, sus motivos de salida y su posterior inserción en el medio costarricense. Nuestro interés radica en identificar sus estrategias de adaptación en una época, 1973-1988, en la que se crearon instancias artísticas con patrocinio del Estado (que posteriormente recortaron su presupuesto) y en la que los grupos debían abrirse espacio frente a un público poco habituado a la tradición teatral.

Palabras clave: Teatro, Exilio, Costa Rica, Chile.

\begin{abstract}
The present work studies two Chilean theater groups based in Costa Rica as a result of the Augusto Pinochet dictatorship: Teatro del Ángel and Teatro Surco. The study is carried out through the reconstruction of brief biographies of the involved artists starting at their country of origin, their motives for fleeing the homeland and their subsequent insertion into the Costa Rican environment. Our interest lies in identifying their adaptation strategies during 1973-1988, a period where artistic instances were created with government sponsorship (the budget would later be eliminated) and in which the artistic groups had to make way and create an audience from a public unaccustomed to theatrical tradition.
\end{abstract}

1 Académica e investigadora de la Universidad Nacional (UNA), Costa Rica. Master en Historia Aplicada por esta Universidad. Este trabajo se difundió como ponencia en las V Jornadas del Exilio Iberoamericano, CIALC, UNAM, México, el 29 de octubre del 2019. ORCID: https://orcid.org/0000-0002-2321-3186 
Keywords: Theater; Exile; Costa Rica; Chile.

\section{Resumo}

Este trabalho estuda a dois grupos de teatro chilenos residentes na Costa Rica como consequência da ditadura de Augusto Pinochet: Teatro del Ángel e Teatro Surco. Para o qual, são reconstruídas breves biografias desses artistas em seu país de origem, suas razões para partir e sua posterior inserção no ambiente da Costa Rica. Nosso interesse reside em identificar suas estratégias de adaptação em uma época, 1973-1988, em que instâncias artísticas foram criadas com patrocínio estatal (cujo orçamento logo depois foi cortado) e nas quais os grupos tiveram que abrir espaço diante de um público não acostumado à tradição de teatro.

Palavras-chave: Teatro; Exílio; Costa Rica; Chile.

\section{Introducción}

Este trabajo estudia dos grupos de teatro chileno radicados en Costa Rica a raíz de la dictadura de Augusto Pinochet: Teatro del Ángel y Surco². Para llevarlo a cabo, se reconstruyen breves biografias de estos artistas en su país de origen, sus motivos de salida y su posterior inserción al medio costarricense. Nuestro interés radica en identificar sus estrategias de adaptación en una época, 1973-1988³ , en la que se crearon instancias artísticas con patrocinio del Estado (que posteriormente recortaron su presupuesto) y en la que los grupos debían abrirse espacio frente a un público poco habituado a la tradición teatral.

Nuestra propuesta también incursiona en las posibles expresiones del exilio mediante sus prácticas, tales como la escritura de obras, selección de repertorios, creación de contactos y grupos, entre otros. Aunque los motivos de salida fueron distintos, consideramos que estos artistas se encontraron en una situación de exilio, porque percibieron una amenaza en su país de origen que los presionó u obligó a su partida, con el propósito de su retorno hasta que las condiciones políticas se transformaran (Sznajder y Roniger, 2013, p. 31). Aunque Teatro del Ángel y Surco vivieron el exilio de manera distinta a lo largo del tiempo, la reubicación en un nuevo país los condujo a trabajar en entornos académicos, con grupos independientes o de forma autónoma, lo cual provocó que en esta búsqueda se plantearan la adaptación al contexto local o el regreso definitivo a su país natal.

2 A Costa Rica también llegaron otros actores y actrices de teatro, entre ellos: Carmen Bunster, Marcia Maicco, Juan Katevas, Alonso Venegas, Rodrigo Durán, Patricio Arenas, Leonardo Perucci, Rosa Zúñiga, Víctor Rojas y Mario Álvarez (Ramírez, 2019, p. 193).

3 Este periodo de la dictadura chilena incluye a ambos grupos. Castro y Sieveking de Teatro del Ángel se marcharon de Costa Rica en 1985, mientras que Gaete y Astica de Surco terminaron su carrera en 2002. 


\section{Alejandro Sieveking, Bélgica Castro, Lucho Barahona y Teatro del Ángel}

Alejandro Sieveking fue un exitoso dramaturgo y director chileno, egresado de la Escuela de Teatro de la Universidad de Chile $(\mathrm{UCH})$ y profesor de Técnica Literaria del Drama e Historia del Teatro Chileno en la Escuela de Teatro de la Pontificia Universidad Católica de Chile (PUC) (Anónimo, 1988). Desde su ingreso a la universidad, desarrolló la escritura dramática estrenando o escribiendo de 1955 a 1973, aproximadamente, una o dos obras por año (Tabla 1). Este campo del teatro lo llevó a trabajar con Víctor Jara y Raúl Ruiz, quienes dirigieron Ánima de día claro (1959), Parecido a la felicidad (1959), Honorato, el caballo del circo (1959), La remolienda en 1964; y la adaptación al cine de Tres tristes tigres en 1967, respectivamente.

A estas alturas, la dramaturgia de Sieveking había incursionado en diversas corrientes. Siguiendo a Castedo (1982), se introdujo en el folklorismo con las obras Ánimas de día claro (1959) y El Cheruve (1965); en la comedia con La remolienda (1964); en el neorrealismo psicológico con Mi hermano Cristián (1957), La madre de los conejo (1961), Parecido a la felicidad (1959), Tres tristes tigres (1967) y en la experimentación de la estructura dramática con Todo se irá, se fue, se va al diablo (1968)4. Por tanto, este autor había transitado por temas alusivos a leyendas araucanas, mitos populares en Talagante, personajes campesinos en embrollos amorosos, conflictos intrafamiliares, triángulos amorosos, desesperanza por necesidades económicas y juegos con la temporalidad pasado-futuro.

En 1971 integró una agrupación al lado de los actores Ana González, Luz María Sotomayor, Bélgica Castro, Lucho Barahona y Dionisio Echeverría que se llamó Teatro del Ángel. El grupo adquirió el antiguo cine Teatro San Antonio, en Santiago y, con el objetivo de liquidar la deuda de 800 millones de escudos, realizaron espectáculos cada noche con obras como La mantis religiosa, La virgen de la manito cerrada y Cama de batalla de Sieveking; Toruvio el ceniciento de Barahona; El botín de Joe Orton; La profesión de la señora Warren de Bernard Shaw; La Celestina de Fernando de Rojas; Gato por liebre de Georges Feydeau y Espectros de Henrik Ibsen (Anónimo, 1974 y Memoria Chilena de la Biblioteca Nacional de Chile, 2020, Alejandro Sieveking (1934-2020). Presentación).

El trabajo teatral de Sieveking y Castro los galardonó con el Gran Premio de la Crítica Chilena en 1973 en dirección/dramaturgia y actuación, respectivamente (Anónimo, 1974; Morales, 1974). Es importante remarcar que en este grupo destacaba la figura

4 En 1968 también colaboró junto con José Pineda en Peligro a 50 metros del Taller de Experimentación Teatral (TET) de la Escuela de Artes de la Comunicación de la UCH, una obra enfocada en la violencia de la guerra de Vietnam (Hurtado, Vidal y Ochsenius, 1982) y considerada como una de las primeras (sino la primera) de creación colectiva (Pradenas, 2006). 
de Castro, quien se desempañaba como profesora de Historia del Teatro en el Instituto de Teatro de la Universidad de Chile (ITUCH) y de actuación en la Escuela de Teatro de la PUC, oficio con el que conoció a sus estudiantes Sieveking y Barahona (Barahona, comunicación personal, 24 de enero del 2019). También fue fundadora del Instituto del Teatro (1941) y de la Escuela de Teatro (1952) de UCH; estuvo en la BBC de Londres como actriz en el Programa para América Latina (1949); trabajó con El Galpón (1956) en Las tres hermanas de Antón Chejov y con Ictus (1963) en La visita de la vieja dama de Friedrich Dürrenmatt; formó parte del Teatro Experimental ${ }^{5}$, y construyó un renombre con sus actuaciones en Casi casamiento de Daniel Barros Grez, Chañarcillo de Antonio Acevedo Hernández, Mama Roda de Fernando Debessa, Fulgor y muerte de Joaquín Murieta de Pablo Neruda, Coronación de José Donoso, Mala onda de Alberto Fuguet, Cabeza de ovni de Manuela Oyarzún y La Celestina de Fernando Rojas (Memoria Chilena de la Biblioteca Nacional de Chile, 2020, Bélgica Castro, 1921-2020).

Barahona y Echeverría, por su parte, se destacaron por la versatilidad de sus habilidades en la agrupación. Así, por ejemplo, el primero era reconocido por su capacidad de resolver las demandas actorales de distintos personajes a tono con un "actor polifacético", así como por su talento en el diseño y dibujo de afiches, vestuarios y escenografías. El segundo sobresalió por su facilidad para la comedia, la administración, las relaciones públicas y la publicidad, aspectos indispensables en la producción de espectáculos (Anónimo, 1974). Ambos habían trabajado en Panamá durante un año, junto con Eduardo Barril, en un programa televisivo llamado el Payasito Beltroldo, dirigido al público infantil (Anónimo, 1972).

El éxito del grupo se interrumpió en 1974 cuando Castro, Sieveking, Barahona y Echeverría salieron de Chile debido al golpe. Para entonces, los militares asesinaron a Víctor Jara, amigo cercano de Sieveking, y Barahona experimentó el allanamiento de su departamento ${ }^{6}$ (Barahona, 2019). Castro explicó la partida "por el golpe, aunque no pertenecemos a ningún partido político. Mataron a Víctor Jara, quien nos estaba dirigiendo una obra [La virgen del puño cerrado], y yo me volví medio loca" (Sotomayor, 1997, p. 10) y con quien habían trabajado en Parecido a la felicidad, Ánimas de día claro, La Remolienda, entre otras (Jurado y Morales, 2003, pp. 47-50). Sieveking, asimismo, recordó que "fue una etapa terrible. Estábamos en el teatro, montando "Espectros", y llegaron a detener a una de las actrices. ¡Se la llevaron vestida de época!” (Sotomayor, 1997, p. 10).

5 El Teatro Experimental se conoció como: Instituto de Teatro de la Universidad de Chile (ITUCH, 1959), Departamento de Teatro de la Universidad de Chile (DETUCH, 1969), Compañía de Teatro Nacional (1974) y Teatro Nacional Chileno (TNCH, 1975) (Facultad de Artes de la Universidad de Chile, Historia, 2019).

6 De acuerdo con Barahona, los soldados allanaron su apartamento acusándolo de arrojar una semilla de durazno contra un tanque militar que patrullaba la zona (Barahona, comunicación personal, 17 de marzo del 2017). 
Después de una estancia en Río de Janeiro, gracias a la hospitalidad del hermano de Sieveking y al considerar el ascenso de las dictaduras latinoamericanas, el grupo partió a Costa Rica, conocida en una gira previa ${ }^{7}$ y atractiva por la ausencia de ejército. Para lograr su salida de Chile, Teatro del Ángel diseñó una gira internacional por América Latina, argumentó, ante las autoridades militares y aduaneras, que el toque de queda imposibilitaba la afluencia de público (Barahona, 2019). Aunque el motivo, como lo vimos en las palabras de Castro y Sieveking, era el temor a la detención, tortura y desaparición, identificadas ya en algunos de sus compañeros y compañeras.

En Costa Rica, el grupo recibió apoyo de la directora del Teatro Nacional (TN), Graciela Moreno, y de la ministra de Cultura, Carmen Naranjo. La directora del Teatro Nacional, Moreno, especializada en dirección escénica e iluminutécnica en México, había visto el montaje de La Celestina de Fernando de Rojas en una de las giras de la agrupación (Barahona, 2019). Por esto, a solicitud de Moreno, uno de los primeros montajes del Ángel en nuestro país fue la adaptación de esta obra de José Ricardo Morales, una versión para teatro cámara y que para entonces se realizó con cinco actores (Sieveking, 1980). Así el panorama, esta directora ofreció el patrocino de obras café-concert en la cafetería del TN que Barahona recordó de la siguiente manera:

Entonces, nos dijo, veamos el camarín de ustedes, y era una oficina que estaba al frente del café. Fuimos a conocer el café y ella puso una tarima en el café, puso reflectores, y como es pequeñito no tenía necesidad de micrófono ni nada... nosotros nos vestíamos en otro lado y mirábamos qué pasaba. La Nación nos ayudó montones, poníamos anuncios grandes, que decían vaya al Teatro Nacional, a ver café concert, se van a divertir. Entonces nosotros dijimos, qué va a pasar si la gente no está acostumbrada al teatro, se llenaba, eran las 8:30 de la noche y se repletaba...y la gente se sentaba en las mesas, comía sándwich, comía cosas, tomaba birra, tomaba todo y lo pasaba fantástico, nos dejaban un camino para pasar nosotros al escenario, a la pequeña tarima, y ahí nos hicimos el espectáculo. (Barahona, 2019, comunicación personal)

Por otro lado, Naranjo, reconocida escritora nacional, facilitó contactos para que del Ángel obtuviera fuentes de financiamiento (Barahona, 2019). De esta manera, sus integrantes adquirieron un crédito con el Banco de Costa Rica para comprar un local en Cuesta de Moras, el cual transformarían en sala de teatro (Loaiza, 1976); y también, al igual que otros artistas, recibieron una subvención anual de $\$ 48$ 000 del Ministerio de Cultura (Anónimo, 1978; Anónimo, 1979) para gastos de

7 De acuerdo con Loaiza, Sieveking fue quien había conocido nuestro país previamente, aunque no precisa la fecha y los motivos de esta visita (Loaiza, 1976). 
operación, propia de las políticas de mecenazgo del Estado benefactor en la década de 1970 (Cuevas, 1996). Así, del Ángel, precedido por Teatro Arlequín, fue uno de los primeros grupos en marcar una "geografía teatral" en el imaginario cultural, el cual empezaba a ubicar el teatro comercial en el "circuito" de Cuesta de Moras (Fumero, 2016).

Al poco tiempo de su estadía, artistas del Ángel fueron galardonados con los premios nacionales (Tabla 2). Por ejemplo, Barahona recibió el premio a mejor actor de reparto en 1975, mejor actor en 1976 y mejor escenografía en 1984. Mientras que Sieveking obtuvo los reconocimientos a mejor director en 1976, 1981 y 1984. Y, en conjunto, recibieron el premio a mejor grupo en 1977, 1981 y 1984 (Cortés y Murillo, 1992).

Para estas fechas, el grupo chileno había trabajado temporalmente en actuación y dirección en la Universidad de Costa Rica (UCR) (Ramírez, 2019). Así, por ejemplo, Castro laboró en la cátedra de actuación de la Escuela de Artes Dramáticas (EAD) en 1975 y dirigió El gorro de cascabeles de Luigi Pirandello en 1975, Con el amor no se juega de Alfredo de Musset en 1978, El Cruce sobre el Niágara de Alonso Alegría en 1980 y Las tres hermanas de Anton Chejov en 1982 en el Teatro Universitario (TU). Sieveking fue profesor de puesta en escena en 1977 y participó en las obras mencionadas como actor, vestuarista, escenógrafo y traductor. Asimismo, Barahona participó en el elenco de El gorro de cascabeles y en el diseño de escenografía y programas de esta obra y Las tres hermanas (Escuela de Artes Dramáticas, Teatro Universitario, 2019) ${ }^{8}$.

Aparte de estas participaciones individuales y esporádicas en la academia al inicio de su arribo, el grupo se concentró en la rentabilidad de su teatro independiente9 Con la elección de "espectáculos entretenidos", a través de la comedia o del café concert, según Barahona, "rompimos la barrera de las 100 funciones por primera vez en Costa Rica y hoy en día es lo más natural llegar a las 200 presentaciones, pero hace diez años no era así" (Anónimo, 1985, p. 25). En ese sentido, del Ángel descubrió en el café concert una opción para cautivar al público con escenas cortas, cómicas y críticas, cuya mezcla de brevedad y risa posiblemente contribuyó a su aceptación (Barahona, 2019).

Incluso, hacia 1978 recibieron una oferta del empresario Ramón "Moncho" Coll para crear una telenovela cómica, llamada Hay que casar a Marcela. Esta telenovela

8 Castro fue profesora de actuación en los talleres populares del MCJD en 1983 y auxiliar de docencia en la Escuela de Arte Escénico de la UNA en 1984 (Archivo de Recursos Humanos, Bélgica Castro, UNA). Sieveking también dirigió Murámonos Federico de Joaquín Gutiérrez con la CNT (Compañía Nacional de Teatro, 2011).

9 Para conocer este y otros aportes del grupo al medio teatral, consultar Morrúa, 2019, pp. 158-163. 
escrita y producida por Sieveking, protagonizada por Eugenia Fuscaldo y con la participación de Barahona, Arabella Salaverry, Carlos Catania y Jorge Arroyo, entre otros (Bermúdez, 2017) tuvo un gran éxito de audiencia (Barahona, 2019). En este punto, debemos recordar que Sieveking, Castro y Barahona portaban una importante destreza en la televisión, pues cada uno había trabajado en proyectos como programas infantiles para el Canal 9 (El payasito Bertoldo, actuado por Barahona) y series televisivas (Juani en sociedad, El Guardiola y La sal del desierto; escritas por Sieveking y actuadas por Castro) para Canal 13 y Televisión Nacional de Chile (TVN) (Anónimo, 1972; Anónimo, 1988; Memoria Chilena de la Biblioteca Nacional de Chile, 2020, Alejandro Sieveking (1934-2020). Guiones) (Tabla 3).

A pesar de la notoriedad alcanzada en el teatro y la televisión con las comedias, en Costa Rica, a diferencia de Chile, se enfrentaron a las preferencias del público por el cine y a la ausencia de una tradición que fomentara el gusto por el teatro (Barahona, 2019). Esta particularidad fue una de las razones para anunciar en $1980^{10} \mathrm{su}$ partida rumbo a Europa en busca de "nuevos públicos" y "nuevas experiencias". Lo anterior se explicó porque tenían gran acogida con obras como Hablemos a calzón quitado, Ja jaque mate y Corrongísimo; mientras que Espectros, Los cuentos de don Friolera, Cama de batalla y Pequeños animales abatidos no solventaban los costos del montaje y de la planilla (Salvatierra, 1981).

Esta inasistencia, traducida en menor difusión y recuperación de ingresos, planteaba otra limitante para los teatros independientes. El escaso presupuesto, de acuerdo con Castro, restringía la contratación de un gran elenco o la oferta de un repertorio (Tabla 4) con obras reconocidas:

El problema clave para los teatros independientes como el nuestro, en que el movimiento de dinero que entra por boletería alcanza a los 600 mil cólones al año, más una ayuda de 40 mil colones que nos proporciona el Ministerio de Cultura, con lo cual tenemos que sobrellevar absolutamente todos nuestros gastos... es que nos vemos restringidos casi siempre por el número de personajes en las obras que programamos... casi nunca podemos hacer las grandes obras de la literatura teatral que nos son tan queridas y conocidas. (Castro, 1979, p. 25)

Estas palabras de Castro se pueden comprender con la reflexión de Gallina, para quien los dramaturgos exiliados de Argentina y, añadimos, los artistas exiliados de Chile, fueron "forzosamente separados de su contexto de producción", lo que provocó una ruptura con la práctica relacional de su "localidad" y con el "sitio enunciativo" de sus obras (Gallina, 2018, p. 85). El exilio, en el caso de Sieveking y del Ángel,

10 Barahona recuerda que la partida de Castro y Sieveking en 1984 se debió al deseo de reencontrarse con sus familias, específicamente con el hijo de Castro. 
les enfrentó a un contexto local limitado, en el que no siempre posicionaron con la misma rentabilidad las comedias y los dramas. Aunque el grupo reinventó ${ }^{11}$ su trabajo con espectáculos de entretenimiento (comedia, café-concert y programas de televisión), cuya popularidad publicitara otras obras y garantizara su sostenibilidad a largo plazo; esto no significó que sus exigencias estéticas se pudieran potenciar como en la escena chilena y su habitual afluencia de público.

Así lo observamos en 1980, cuando Castro reveló que uno de los motivos de la partida del grupo era el insuficiente desarrollo de las expectativas artísticas en nuestro país:

\begin{abstract}
Asistirán a un festival teatral en Barcelona y participarán en un encuentro de teatro; en octubre, posiblemente, abrirán la sala en Madrid, como lo hicieron acá... la decisión se tomó por varias razones, pero fundamentalmente [palabras de Castro] "por la imposibilidad de hacer el tipo de repertorio que a nosotros nos interesa”. El público costarricense $\square$ comentaron $\square$ responde masivamente a nuestras presentaciones de teatro liviano, mientras obras como Pequeños animales abatidos, de Sieveking, interesantes a nuestro juicio, escasamente llegan a las 50 funciones" [palabras de Castro] "En Costa Rica no somos un teatro chileno, sino costarricense; en Madrid \agregó la actriz $\llbracket$ tenemos un mercado mucho mayor de chilenos que viven fuera de la patria y eso permitirá una amplitud de repertorio". (Anónimo, 1980, p. 6A)
\end{abstract}

Castro y Sieveking volvieron a Chile en 1984 para trabajar en la escritura de guiones (de telenovelas o series) y en actuación, respectivamente, en TVN (Sotomayor, 1997). Ante esta partida, Barahona contactó al gerente "Moncho" Coll para producir y protagonizar el programa La lucha de Lucho, utilizado también por el actor para patrocinar las obras del Ángel. Finalmente, Barahona abandonó la televisión ante la dificultad de coordinar ambas producciones (teatro y televisión) y se dedicó a realizar giras con obras de teatro para, en la década de 1990, comprar un nuevo local que llamaría Teatro Lucho Barahona (Barahona, 2019).

Como podemos observar, la vivencia del exilio en estos artistas se reflejó en el intento de consolidar un teatro independiente que retomara sus aprendizajes de la Escuela de Teatro de la UCH y su experiencia en la administración de un local propio en Santiago. Esta adaptación implicó estrechar contactos con funcionarias públicas (Moreno y Naranjo), explorar la academia (UCR) y diseñar repertorios para un público especialmente atraído por la comedia (teatro) y la telenovela (televisión). En ocasiones, este trabajo alternó el teatro independiente con la producción televisiva (como una fuente alternativa de ingresos) y los reorientó a otros géneros

11 De acuerdo con Gallina (2018), entendemos esta reinvención bajo la premisa de que "lo que hacen los dramaturgos [artistas] exiliados es reinventar en sus prácticas y en su escritura un nuevo modo de habitar un territorio, un intento de reconstrucción en la lejanía (p. 92). 
(o contexto de producción) que acotaban sus intereses en dramaturgia, actuación y puesta en escena.

Por otro parte, la vivencia del exilio también se puede identificar en otras "formas de representación" (Sznajder y Roniger, 2013, p. 54) como la dramaturgia y el sentido de grupo. Con respecto a la primera, podemos mencionar Pequeños animales abatidos (1974) ${ }^{12}$ de Sieveking, una obra con personajes vinculados al mundo del teatro (Felipe: director y escritor de teleseries y teatro; Nancy: actriz) en el Chile de agosto y setiembre de 1973, donde se muestra un contexto, sino biográfico, al menos conocido por el autor y del Ángel. A través de Nancy, Sieveking nos conduce por los disturbios en las calles, la incertidumbre de un golpe de Estado y las múltiples interpretaciones de los sucesos; mientras que con Pelusa (vidente) nos acerca a cuerpos vestidos de blanco (posibles desaparecidos), a la traición estadounidense (Willy) y a la revelación de un largo viaje (¿exilio o muerte?) para Felipe y Nancy. Pareciera, entonces, que Sieveking plantea un texto para "explicar o explicarse" lo ocurrido (Doménech, 2013, p. 24), haciendo frente a la "tarea casi imposible de narrar el exilio" y reconstruir memorias de "individuos desplazados" (Sznajder y Roniger, 2013, p. 54) o "subjetividades laceradas" (Gallina, 2018, p. 92).

Con respecto a la segunda "forma de representación", podemos identificar que en la puesta en escena de esta obra sus actores Barahona, Marcia Maiocco, Katevas, Castro y Sieveking, a excepción de Fuscaldo, eran chilenos (Cañas, 1978). Lo anterior se puede explicar porque la práctica teatral fue "un modo de habitar algo común, cuando justamente no hay un territorio geográfico común a ser habitado. Cuando los vínculos se han quebrado, cuando el exilio ha pulverizado una compleja trama de relaciones" (Gallina, 2018, p. 92), con la actuación de sus compatriotas se puede corporeizar una situación política y una necesidad comunicativa compartidas. La (re)construcción de estos vínculos con la chileneidad y el gremio teatral se puede relacionar también con la participación de Carmen Bunster, Alonso Venegas (Morrúa, 2014), Sara Astica, Patricio Arenas y Marcelo Gaete en otras de sus obras (Anónimo, 1979), lo cual convirtió a del Ángel en un espacio de empleos temporales y sociabilidades en un momento igualmente de exilio para estos artistas escénicos.

Esta colectividad del teatro fue buscada por Castro y Sieveking en su retorno. Ellos se integraron al grupo El Conventillo para estrenar La comadre Lola en 1985, con la aspiración, posiblemente, de tejer vínculos personales o profesionales y asumir el desafío de regresar a la escena chilena. Así lo vemos en las palabras de Sieveking, quien reconoció que "a toda la gente de teatro le hace falta estar en un grupo"

12 Esta obra ganó el Premio Casa de las Américas en 1975, se estrenó en las Jornadas Culturales de Salvador Allende en México en 1978 y se presentó en Costa Rica ese mismo año (Herra, 1978; Rabell, 1978). En Costa Rica también escribió Volar con solo un ala (1976), El uno para el otro (1979) y La diablada (1981). 
(Carvajal, 1985, p. 15) y que esta obra en particular la escribió para "sentirme como que estaba acá [en Chile]" (Carvajal, 1985, p. 15).

Castro, desde la actuación, y Sieveking, desde la dirección y dramaturgia, aparecieron con personajes populares ubicados en el Santiago de finales de los años 50 y con un realismo folclórico distintivo del dramaturgo en el país del sur. Este regreso puedo simbolizar el abandono de la otredad y la extrañeza que se instaura al radicarse en un nuevo país (Sznajder y Roniger, 2013, p. 347) como Costa Rica, pues según declaraba Sieveking "uno siempre es extranjero fuera" y, aún en el exterior, la mayoría de sus obras se ambientaron en Chile, porque esa era la realidad que le resultaba propia y porque ese era el "público [chileno]" para el que estuvieron pensadas (Grandé, 1989, p. 3). Siendo así, este estreno lo posicionaba en Chile con una estética característica del dramaturgo y con la que esperaba reencontrarse con su público espectador, recuperando así parte de una identidad artística interrumpida por el exilio ${ }^{13}$.

\section{Sara Astica, Marcelo Gaete y Teatro Surco}

Astica y Gaete se acercaron a la actuación en Chile desde experiencias distintas. Astica había estudiado pedagogía en castellano en la UCH y después teatro en la PUC, lo que permitió su incorporación al elenco de Teatro de Ensayo de 1960 a 1968 y de forma ocasional hasta 1974. También había trabajado en radioteatro (1952-1955) con Radio El Pacífico y la Compañía Aníbal Reyna; en actuación (1956-1959), con las compañías Lucho Córdoba, Silvia Piñero, Silvia Oxman y Américo Vargas, y en cine y televisión (1957-1972) (Bonilla, 2009; Escuela de Artes Dramáticas, 2007). Esta experiencia se vería reflejada en nuestro país a través de sus actuaciones en teatros independientes y estatales; así como en su incorporación en 1977 a la docencia en la Escuela de Estudios Generales y de la EAD de la UCR en las áreas de actuación, producción y expresión vocal (Bonilla, 2009), en donde produjo con TU el programa En Escena dedicado a entrevistar a personas de teatro y difundir guiones de estudiantes con la modalidad de radioteatro (Ramírez, 2019).

Gaete, por su parte, se desempeñó primero en el Departamento de Orientación del Ministerio de Educación y en la Sección de Despacho de Correo y Telégrafo. Luego, ingresó a la carrera de Teatro de la PUC en 1952 y, después de su deserción, recibió un curso intensivo con Teodoro Lowey. Junto con Astica, Rafael Benavente y Aníbal Reyna conformaron el grupo de teatro El Ateneo de Chile en 1955 y, al mismo tiempo, trabajó en el Teatro Experimental de la UCH y el Teatro Nacional Escénico de la Municipalidad de Santiago (Bermúdez, 1991). Finalmente, alternó

13 Un artículo anónimo menciona que Sieveking recorrió Chile con La remolienda en 1988, una de sus obras más conocidas y de gran éxito de audiencia antes de su partida; esta vez a cargo del Teatro Itinerante del Ministerio de Educación (Anónimo, 1988). 
el oficio del teatro con la producción, actuación y dirección de telenovelas de 1966 a 1975, aproximadamente (Rodríguez, 2004).

De acuerdo con el recuerdo de su hijo, Marcelo Gaete Astica, sus padres tuvieron una formación y perspectiva distintas del grupo anteriormente estudiado. El Ángel, por ejemplo, se vinculó con el Instituto de Teatro de la Universidad de Chile (ITUCH), el que, según Piña (2014), era heredero de otros departamentos universitarios como Teatro Experimental y Teatro Nacional. Este espacio se orientó más a la docencia, investigación y difusión del "teatro clásico y moderno", la dramaturgia chilena, la historia del teatro chileno, los textos teóricos y prácticos; así como a la creación de grupos locales a través de festivales, revistas, programas de radio, charlas y giras (Piña, 2014). Los integrantes de Surco, por su parte, recibieron clases particulares con Lowey, un reconocido actor y profesor de actuación en la Academia de Teatro Ensayo de la PUC, la cual se enfocaba en una enseñanza especializada de tres años (en expresión corporal, voz e historia) en realismo-naturalismo, con la finalidad de que sus actores se incorporaran al movimiento teatral (Piña, 2014). Para Gaete Astica:

El Teatro El Ángel era como un desprendimiento de la Escuela de Teatro que se había fundado en la Universidad de Chile, el ITUCH -Instituto de Teatro de la Universidad de Chile-, con los cuales mis dos padres, por diversas razones, no compartían su línea teatral desde ningún punto de vista con la gente del ITUCH. Mi madre porque siempre había trabajado con la Escuela de Teatro de la Universidad Católica; y mi padre siempre trabajó solo o como actor contratado en puestas de escena del teatro profesional y no en el teatro universitario, o bien, él montando sus obras desde el año setenta para acá. Pero antes mis viejos siempre trabajaron en compañías de teatro porque los dos no son graduados de universidad sino son graduados de escuela privada, que era la Escuela Teodoro Lowey. Los actores que venían del mundo profesional, tenían mucha reserva y muchas objeciones a los actores graduados de Universidad y al teatro que las Universidades implementaban, porque lo consideran un teatro 'light', demasiado académico y academizado, y demasiado complejo y que no era como el teatro tenía que ser, libre. (Gaete Astica, comunicación personal, 13 de noviembre del 2019)

Además de esta diferencia, Astica y Gaete se relacionaron con partidos de izquierda en una Suramérica cada vez más asediada por el Plan Cóndor y la Doctrina de Seguridad Nacional. Con base en los testimonios recuperados por Ruiz (1998), sabemos que Gaete, miembro del Partido Socialista de Chile (PS), trabajaba ocasionalmente para ICTUS y el Teatro Municipal, el primero crítico a la dictadura y el segundo 
considerado una cédula del PS ${ }^{14}$. Astica, miembro del PS y del Movimiento de Izquierda Revolucionaria (MIR), refugió a perseguidos de diversas izquierdas (brasileños, tupamaros, militantes del MIR, entre otros) en su casa y les proveyó necesidades básicas (alimentación, vestimenta y cobijo) (Ruiz, 1998). Una vez ocurrido el golpe, ambos fueron detenidos y Astica fue particularmente acusada y torturada por esta casa de seguridad. Según el recuerdo de Gaete, en el 2004:

Habíamos votado por Salvador Allende, habíamos trabajado para él, yo era muy amigo de Allende. Él iba mucho al teatro... [Cuando los apresaron] Nos llevaron con los ojos vendados. No supimos donde era que estábamos. Un día, como a las seis de la tarde, me dicen 'Señor Gaete, se va con sus dos hijos'. 'Y mi señora, ¿se queda aquí?... la Sara me dijo, sacá a los niños de aquí'... Cuando iba a ver a la Sara a la prisión, todas las semanas, tenía que llevar ropa, vestidos... Era de lo más irónico: mientras la Sara triunfaba en la televisión, le sacaban la cresta en la cárcel... Cuando vimos que ya no había salida, que teníamos que dejar Chile, teníamos cinco opciones: Suecia, Cuba, Perú, Venezuela y Costa Rica. Me había conectado y me habían hecho las entrevistas de rigor. La Sara me dijo 'escoge tú que estás afuera'. Nos decidimos por Costa Rica, porque, además de todo lo anterior, no tiene ejército... Yo llegué dos meses después que la Sara, porque la Paula agarró la tifoidea, así que tuvimos que esperar. (Rodríguez, 2004, p. 18)

Con el decreto de expulsión, recibieron el apoyo del embajador de Costa Rica en Chile Tomás Soley y solicitaron asilo político en 1975 (Colección de Leyes y Decretos, Cartera de Relaciones Exteriores, 1975, Acuerdo o Resolución 16, p. 1546; Acuerdo o Resolución 26, p. 958). A su llegada fueron acogidos por Sieveking, Castro, Barahona y Echeverría (Juncos, 2000) y tuvieron varias ocupaciones como vendedores de enciclopedias y empanadas chilenas (Gaete); así como dependientes en la boletería del TN (Astica). Seguidamente, y a veces al mismo tiempo, empezaron a actuar para el TU, Teatro del Ángel, TN, Teatro Arlequín, Compañía Nacional de Teatro (CNT), Teatro Carpa, Teatro La Colina y Teatro Eugenio O'Neil (Astica, 1991); de esa manera se insertaban en el medio teatral.

Tan pronto a su llegada, estos actores fueron galardonados con los premios nacionales en teatro (Figura 2). Si partimos del período 1968-1991, compilado por Cortés y Murillo (1992), observamos que Astica obtuvo el premio a mejor actriz de reparto en 1975 y 1978; así como a mejor actriz en 1978, 1979, 1986 y 1989. Gaete, a su vez, los obtuvo por mejor actor en 1978, 1985 y 1989; mejor actor de reparto en 1979 y mejor dirección en 1989.

14 Ruiz también nos recuerda que Astica y Gaete trabajaron con Carmen Bueno y Jorge Muller en La tierra prometida, película clausurada por la Junta y cuyos compañeros (Bueno y Muller) fueron detenidos-desaparecidos, acusados de apoyar a Juan Bautista Von Shouwen del MIR (Ruiz, 1998). 
Al lado de su carrera actoral, en 1977 Astica y Gaete conformaron el grupo Surco. Similar a Teatro del Ángel, estos chilenos se distribuyeron las tareas de actuación, diseño de vestuario y escenografía, dirección y producción para reducir los $\operatorname{costos}^{15}$; con la diferencia de que no obtuvieron financiamiento estatal. Según Castellón, estos actores se enfrentaron a un mercado laboral saturado de intérpretes en los elencos de la CNT y con escasas funciones en el TU (Castellón, 2007), razón por la que fundaron su propia agrupación. Esta también sería galardonada con el premio nacional a mejor grupo en 1991, 1996 y 2000 (Escuela de Artes Dramáticas, 2007). Según el recuerdo de Gaete, 14 años después de la creación del grupo:

En 1977 ya habíamos trabajado en forma individual en casi todos los grupos costarricenses: Arlequín, El Ángel, Universitario, Compañía Nacional de Teatro, etc. Porque no teníamos sala ni subvención, entonces teníamos que ver de qué manera subvencionábamos nuestro propio espectáculo cuando lo hacíamos... desde el 77 para acá hemos trabajado aproximadamente en trece obras, una por año, mientras trabajamos con otros grupos. Sara trabajó hasta el 86 con la Compañía Nacional de Teatro, hasta que cambiaron a todo el plantel. (Bermúdez, 1991, p. 5)

Astica y Gaete encontraron en Surco una posibilidad para adaptarse culturalmente al país de acogida. En Chile, por ejemplo, actuaron para teatros universitarios y municipales, al tiempo que el desarrollo de la televisión universitaria en la década de 1960 (Hurtado, Edwards y Guilisasti, 1989) los integró en programas dramatizados como teleseries, obras de teatro y telenovelas (Bermúdez, 1991) (Tabla 3). En Costa Rica, en cambio, encontraron un trabajo esporádico con pocas funciones por temporada ${ }^{16}$ y escasos programas de televisión, a pesar de los esfuerzos estatales por crear una compañía (CNT), un teatro al aire libre (del Museo Nacional) y un sistema de radio y televisión (Departamento de Cine, 1973; SINART, 1978). Surco permitió, en ese sentido, abrir una opción laboral en un país que, como lo señalaba Barahona en el apartado anterior, debían de gestionar su propio público y fomentar el interés para que asistiera a sus obras de nuevo. Así lo indica Gaete Astica:

Sobre todo mi padre, trabajó más en Surco porque montaron eso como una oportunidad de auto darse trabajo, y no estar dependiendo siempre de que te llame alguien para un papel, una escenografía o lo que fuera necesario....Siempre vieron Surco como la oportunidad de un trabajo propio, de autonomía y libertad para hacer cosas, porque además nunca tuvieron presupuesto de nadie para hacer eso, fue autogestionado

15 Para conocer este y otros aportes del grupo al medio teatral, consultar Morrúa, 2019, pp. 158-163 y Ruiz, 1998, pp.72, 118-119, 124 y 126).

16 Si tomamos como referencia el período de 1975 (llegada de Astica y Gaete) a 1977 (creación de Surco), la CNT presentó 8 obras en 1975, 1 en 1976 y 4 en 1977 (Compañía Nacional de Teatro, 2011); y el TU 7 en 1975, 3 en 1976 y 5 en 1977 (Escuela de Artes Dramáticas, Teatro Universitario, 2019). Además se cerró el exitoso proyecto de Teatro al Aire Libre del Museo Nacional, vigente desde 1972. 
totalmente, todas las puestas en escena fueron autogestionadas, mediante convenios con Escarpa en zapaterías para conseguir los zapatos, líneas aéreas para financiar así las obras y hasta con la taquilla. (Gaete, 2019)

Al contexto de producción local se sumó la crisis económica de 1980 y los programas de ajuste estructural en 1985, los cuales provocaron recortes en cultura y restricciones para aumentar este presupuesto (Cuevas, 1996), limitaron las subvenciones, la ejecución de proyectos en estas áreas y el capital adquisitivo de un público ya reducido. Lo anterior nos permitiría comprender el argumento de Astica sobre la necesidad de habilitar La Comedia en 1991, una sala que con el respaldo del socio capitalista Carlos Campos Vargas generaría un espacio para profesionales en teatro y para el convivio con el público josefino:

Es algo importante para el medio teatral costarricense que exista una sala, porque hay pocos medios de trabajo para el actor. Aquí no hay televisión, no se hace cine en forma continuada, no hay radioteatros, la única forma de subsistencia de los actores es el teatro, entonces hacer una compañía tratando de que sea exitosa, nos da oportunidad de trabajar a nosotros y a los otros compañeros que se incorporen al elenco. Porque cada año sale gente de las universidades con título de actor y tienen que dedicarse a trabajar en otra cosa porque el teatro no les da fuente de trabajo, eso es un problema serio... no puede un actor vivir del teatro, a menos que sean los cinco o seis "locos" que tratamos de vivir de esto. Esa situación hace que no sea realmente profesional el teatro, porque el actor no puede vivir de su trabajo. En otros países los actores hacen radioteatros, telenovelas, doblan películas, etc., pero aquí sólo hacen teatro, Con una cantidad de actrices estupendas que no tienen trabajo... (Bermúdez, 1991, p. 4)

Esta sala también formó parte de la vivencia del exilio, o del proceso de adaptación que trae consigo, por dos motivos. En primer lugar, se convirtió en un lugar fijo para mostrar sus obras ante la decisión de Astica y Gaete en 1986 de trabajar solo en Surco. En segundo lugar, de acuerdo con Castellón, representó un refugio para enfrentar las pérdidas del exilio, pues, al igual que Surco, era un espacio para la contención física y psicológica necesaria en un "proceso de duelo y desarraigo forzados" (Castellón, 2007, pp. 67, 76-77) en el que "se pierden sus sistemas de referencia" (Vázquez y Araujo, citado por Sznajder y Roniger, 2013, p. 52). Por tanto, Astica, Gaete y sus hijos, a través de las labores del teatro (actuación, dirección y producción), se acompañaron y "reconfiguraron" sus identidades en un medio que estaba lejos del contexto artístico y familiar del que provenían. Aunque cabe señalar que como indica Castellón, el cierre de la sala en el 2002, por problemas de rentabilidad y diferencias con el socio capitalista, también la convirtió en un duelo. 
No obstante, con este espacio buscaron continuidad en sus proyectos, independencia de otras compañías y asentamiento después de 8 años de giras por América (1983: Colombia y Ecuador; 1984, 1985 y 1988: Panamá; 1987: Ecuador, Perú, Chile, y 1990: Canadá, Estados Unidos, Ecuador, Perú y Chile) (Astica, 1991, p. 44), debido al inconveniente de no contar con sala propia. Dicha sala significó, asimismo, subsistir en un país en el que para Astica, en 1991, era difícil el acceso a la vivienda, a la educación y a la salud (sin afiliación a la CCSS), y en el que el trabajo del teatrista, además de inestable, era "considerado poco necesario en la productividad económica y en los dividendos monetarios" (Astica, 1991, p. 41).

Surco, además de ser un núcleo de contención (Castellón, 2007), ofreció autonomía en el repertorio. Así, por ejemplo, escogieron dramaturgos o artistas chilenos como Jorge Díaz, Juan Radrigán, Marco Antonio de la Parra, Violeta de la Parra y Antonio Skármeta (Tabla 5); conservaron, así, un vínculo con Chile para, de alguna manera, "aferrarse a su idioma, a sus costumbres, a sus hábitos sociales" (Oliva, 2012, p. 363), a la vez que compartieron temas, lenguajes y personajes del teatro chileno con el público costarricense (Castellón, 2007).

En 1995, el grupo arribó a Chile para escenificar una obra en Plaza Nuñoa, al lado de Lucho Arenas Godoy y Jaime Troncoso (C.H, 1995). Aunque su primera visita fue en 1987 (Gaete) y en 1990 (Gaete y Astica) (Tabla 6), en este regreso se representó un texto de Radrigán ${ }^{17}$. Además de escoger un dramaturgo chileno, la particularidad de la obra, Isla de porfiado amor (1993), radica en que retomaba sentimientos conocidos por los exiliados ${ }^{18}$, tales como el destierro y la soledad de una pareja (Diego y Micaela), expulsada de la ciudad por falta de trabajo y del desierto al que llegaban por la resistencia de sus muertos (Pulgar, 1994). Este dramaturgo era, además, conocido por crear personajes expulsados de todos los espacios (Hechos consumados, El loco y la triste, Informe para indiferentes, Las brujas), los insertaba en un mundo de aislamiento, marginalidad social y violencia (Hurtado y Piña, 1984). La autodestrucción o la muerte de alguno de sus protagonistas se convertía en la denuncia a un sistema que los despojó de condiciones mínimas de "dignidad" (como sustento, residencia, salud, alimento o relaciones de respeto) y los condujo a una "situación límite" de desesperación y soledad (Hurtado y Piña, 1984), como ya lo habían actuado Gaete y Astica en El loco y la triste en 1989.

17 De acuerdo con Gaete Astica, el interés de sus padres en la poética de Radrigán se puede explicar porque estas obras "condensaban una ética de izquierda" a través de la pobreza de los sectores populares, una orientación afín a la experiencia de sus padres (Gaete Astica, 2019).

18 Para Daniel Gallegos, en obras como Comedia a la antigua, El loco y la triste y Ay, Carmela!, estos actores retoman el tema del exilio, aunque no ahonda al respecto (Ruiz, 1998). 
Esta vez proponemos que la Isla de porfiado amor fue una forma de comunicar el exilio en este regreso a Chile. $\mathrm{O}$ al menos de transmitir sentimientos comunes con los personajes, como la separación de un territorio, el aislamiento en tierra desconocida, la (in)adaptación a nuevos lugares y la espera de un cambio en las circunstancias por 20 años (Anónimo, 1995), tiempo vivido por la pareja en la salitrera y por Gaete y Astica en el exterior hasta esa fecha. Esta obra también pudo significar una batalla de los actores contra el olvido, ya que su regreso los resituaba en el medio (teatral, social y político) al que una vez pertenecieron ${ }^{19}$.

\section{A manera de cierre}

En la década de 1970, Costa Rica fue un lugar de acogida para grupos exiliados chilenos, argentinos y uruguayos. Según algunos de los relatos estudiados, llegaron a este país centroamericano por contactos previos, o bien, por la ausencia de ejército que alejaba la posibilidad de una militarización del poder y eventual dictadura. Al tiempo que estas expulsiones ocurrían, en nuestro país se estaban fundando una serie de instituciones como el MCJD (1971), la CNT (1971) y las Escuelas de Teatro de la UNA (1974) y de la UCR (1968), que coyunturalmente contrataron (de forma temporal) a artistas en exilio como Castro, Sieveking y Astica. Por su parte, Barahona y Gaete, al lado de sus respectivas agrupaciones, exploraron el teatro independiente en la ciudad josefina, otra veta del campo especialmente inestable, si tomamos en cuenta que los gustos del "gran público" apenas empezaban a promoverse desde estas instituciones estatales.

Ambos grupos eran portadores de una amplia experiencia en teatro y televisión, específicamente en las áreas de actuación, dirección y dramaturgia (Sieveking). Aunque cabe aclarar que desde tradiciones distintas: del Ángel emparentado con el quehacer académico del ITUCH y Surco con la especialización actoral de la escuela privada de Lowey. Estos artistas habitaron el nuevo territorio del exilio ensayando diversas estrategias, tales como la apertura de salas, la (re)elaboración de repertorios, la búsqueda de alianzas con la empresa privada y la participación en otros espacios (como la televisión para el Ángel y la docencia universitaria para Astica). Estas adaptaciones, si bien reinventaron su trabajo artístico en un país con un público interesado en comedias (tanto teatrales como televisivas), también era una forma de recuperar los aprendizajes y las prácticas que habían desarrollado en Chile. Al fin y al cabo, Chile no estaba tan lejos, pues como lo observamos en estos proyectos, en

19 Recuerda Gaete Astica que no era tan fácil regresar allá y ser aceptados por el medio teatral chileno o la televisión, que en ese tiempo también había cierto recelo con respecto a los chilenos que regresaban lo que decían ellos: ¿volver a Chile a empezar de cero de nuevo, a crear una compañía, a visibilizarse en la escena local nuevamente a pesar de que tenían mucha fama antes de irse?'” ( Comunicación personal Gaete Astica, 2019).

180 Revista Latinoamericana de Derechos Humanos 
la selección de dramaturgos, en la escritura de algunas obras y en los montajes a su regreso, existió una necesidad de compartir su preparación teatral; comunicar los sentimientos asociados al exilio; y mantener vínculos a través de temas o personajes con su país natal.

\section{Anexos}

Tabla 1. Dramaturgia de Sieveking, 1955-1978

\begin{tabular}{|c|c|}
\hline Año & Obra \\
\hline 1955 & $\begin{array}{l}\text { Encuentro con las sombras } \\
\text { Una plaza sin pájaros }\end{array}$ \\
\hline 1957 & $\begin{array}{l}\text { El paraíso semiperdido } \\
\text { La lección de la luna } \\
\text { Mi hermano Cristián }\end{array}$ \\
\hline 1958 & $\begin{array}{l}\text { Fin de febrero } \\
\text { Cuando no está la pared } \\
\text { La abuelita encantada } \\
\text { La coronación de Pierot }\end{array}$ \\
\hline 1959 & $\begin{array}{l}\text { Ánima de día claro } \\
\text { Parecido a la felicidad } \\
\text { Honorato, el caballo del circo }\end{array}$ \\
\hline 1961 & $\begin{array}{l}\text { La madre de los conejos } \\
\text { La cama en medio de la pieza } \\
\text { La gran batalla del Living }\end{array}$ \\
\hline 1962 & Dionisio \\
\hline 1963 & $\begin{array}{l}\text { Los hermanastros I } \\
\text { Los hermanastros II }\end{array}$ \\
\hline 1964 & $\begin{array}{l}\text { La remolienda } \\
\text { Piel de asno } \\
\text { Manuel Leónidas Donaire y las cinco mujeres que lloran por él }\end{array}$ \\
\hline 1967 & Tres tristes trigos \\
\hline 1968 & $\begin{array}{l}\text { Todo se irá, se fue, se va al diablo } \\
\text { Una vaca mirando el piano }\end{array}$ \\
\hline 1971 & La mantis religiosa \\
\hline 1973 & La virgen de la manita cerrada \\
\hline
\end{tabular}

Nota: Memoria Chilena de la Biblioteca Nacional de Chile (s. f.). Alejandro Sieveking (1934-2020). Cronología. 


\section{Tabla 2. Premios nacionales en teatro recibidos en Costa Rica, 1975-1989}

\begin{tabular}{|c|c|c|}
\hline Nombre & Categoría & Año y obra \\
\hline \multirow{3}{*}{$\begin{array}{l}\text { Lucho } \\
\text { Barahona }\end{array}$} & $\begin{array}{l}\text { Mejor actor } \\
\text { de reparto }\end{array}$ & $\begin{array}{l}\text { 1975: El gorro de cascabeles de Luigi Pirandello, } \\
\text { posiblemente con TU. }\end{array}$ \\
\hline & Mejor actor & $\begin{array}{l}\text { 1976: Gato por liebre de George Feydeau, Espectros de } \\
\text { Henryk Ibsen y Hablemos a calzón quitao de Guillermo } \\
\text { Gentile, con Teatro del Ángel. }\end{array}$ \\
\hline & $\begin{array}{l}\text { Mejor } \\
\text { escenografía }\end{array}$ & $\begin{array}{l}\text { 1984: El zoológico de cristal de Tennesse Williams, con } \\
\text { Teatro del Ángel. }\end{array}$ \\
\hline $\begin{array}{l}\text { Alejandro } \\
\text { Sieveking }\end{array}$ & $\begin{array}{l}\text { Mejor } \\
\text { director }\end{array}$ & $\begin{array}{l}\text { 1976: La virgen del puño cerrado de Alejandro Sieveking, } \\
\text { con Teatro del Ángel. } \\
\text { 1981: El hombre elefante de Bernard Pomerance, con } \\
\text { Teatro del Ángel. } \\
\text { 1984: El zoológico de cristal de Tennesse Williams, con } \\
\text { Teatro del Ángel. }\end{array}$ \\
\hline \multirow[b]{2}{*}{$\begin{array}{l}\text { Sara } \\
\text { Astica* }\end{array}$} & $\begin{array}{l}\text { Mejor actriz } \\
\text { de reparto }\end{array}$ & $\begin{array}{l}\text { 1975: María Estuardo de Frederich Von Schiller, con TU. } \\
\text { 1978: Invitación al castillo de Jean Anouilh, con la CNT. }\end{array}$ \\
\hline & Mejor actriz & $\begin{array}{l}\text { 1978: Querido mentiroso de Jerome Kilty, con Teatro } \\
\text { Surco. } \\
\text { 1979: Esperando a Godot de Samuel Beckett con la CNT y } \\
\text { la colaboración de la Alianza Francesa. } \\
\text { 1986: Sara Bernhardt de John Murrel con Teatro Surco. } \\
\text { 1989: El loco y el triste de Juan Radrigán con Teatro Surco. }\end{array}$ \\
\hline \multirow{3}{*}{$\begin{array}{l}\text { Marcelo } \\
\text { Gaete** }\end{array}$} & Mejor actor & $\begin{array}{l}\text { 1978: La visita del inspector de John Boynton Priestle, con } \\
\text { Teatro Arlequín } \\
\text { 1985: El perfecto seductor de Neil Simon con Teatro Surco. } \\
\text { 1989: El loco y la triste de Juan Radrigán con Teatro Surco. }\end{array}$ \\
\hline & $\begin{array}{l}\text { Mejor actor } \\
\text { de reparto }\end{array}$ & $\begin{array}{l}\text { 1979: Murámonos, Federico de Joaquín Gutiérrez, con la } \\
\text { CNT. }\end{array}$ \\
\hline & $\begin{array}{l}\text { Mejor } \\
\text { dirección }\end{array}$ & 1989: El loco y la triste de Juan Radrigán con Teatro Surco. \\
\hline
\end{tabular}

Nota: Cortés y Murillo, 1992, pp. 76-77. *En el período de estudio, Astica también en: La virgen del puño cerrado de Sieveking (1976, Teatro del Ángel), La gaviota de Anton Chejov (1977, Teatro Arlequín), Las reinas de Francia de Thronton Wilder (1977, TU), El diario de Ana Frank de Goodrich y Hackett (1977, TN y Asociación de Damas Israelitas), Georges Dandin o el marido humillado de Moliere (1977, Teatro Arlequín), Con el amor no se juega de Alfred de Musset (1978, TU), Ok de Isaac Chocron (1980, TU), La loca de Chaillot de Jean Giraudoux (1980, CNT), Los bajos fondos de Máximo de Gorki (1980, CNT), Divinas palabras de Ramón Valle Inclán (1981, CNT), El cilindro de Eduardo de Filippo (1983, TU). (Escuela de Artes Dramáticas, 2007, pp.6-7). **Astica menciona que Gaete recibió el premio a mejor actor de reparto por Topografía de un desnudo de Jorge Díaz (Astica, 1991, p. 44-45). 
Tabla 3. Actuación en cine y teleseries en Chile, antes de su llegada a Costa Rica

\begin{tabular}{|c|c|c|}
\hline Nombre & \multicolumn{2}{|c|}{ Año y película } \\
\hline $\begin{array}{l}\text { Bélgica } \\
\text { Castro }\end{array}$ & $\begin{array}{l}\text { Cine } \\
\text { 1970: El fin del juego } \\
\text { 1973: Palomita blanca }\end{array}$ & $\begin{array}{l}\text { Teleserie } \\
\text { 1967: Juani en soledad } \\
\text { 1969: Guaripola } \\
\text { 1972: La sal del desierto }\end{array}$ \\
\hline $\begin{array}{l}\text { Alejandro } \\
\text { Sieveking }\end{array}$ & $\begin{array}{l}\text { Teleserie } \\
\text { 1972: La sal del desierto }\end{array}$ & \\
\hline $\begin{array}{l}\text { Lucho } \\
\text { Barahona }\end{array}$ & $\begin{array}{l}\text { Teleserie } \\
\text { 1972: La sal del desierto } \\
1972 \text { (segundo estreno): El pay }\end{array}$ & Bertoldo \\
\hline Sara Astica & $\begin{array}{l}\text { Cine } \\
\text { 1957: La caleta olvidada } \\
\text { 1966: El aborto } \\
\text { 1967: Angelito } \\
\text { 1968: Valparaíso mi amor } \\
\text { 1972: En este pueblo no hay lac } \\
\text { Teleseries } \\
\text { 1966: Juntos se pasa mejor } \\
\text { 1967: Esa mujer eres tú } \\
\text { 1968: El socio } \\
\text { 1968: Amalia } \\
\text { 1968: Lilias, azucenas, un crim } \\
\text { 1969: La chica del bastón, Don } \\
\text { 1970: El padre Gallo, El libro o } \\
\text { 1971: La amortajada } \\
\text { 1972: La sal del desierto, Puert } \\
\text { Domingo }\end{array}$ & $\begin{array}{l}\text { y estado de sitio } \\
\text { Sin amor } \\
\text { ttro, Lecho nupcial y Teatro del }\end{array}$ \\
\hline $\begin{array}{l}\text { Marcelo } \\
\text { Gaete }\end{array}$ & $\begin{array}{l}\text { Cine } \\
\text { 1957: Tres miradas a la calle } \\
\text { 1958: La caleta olvidada } \\
\text { 1960: Un viaje a Santiago } \\
\text { 1971: Voto+fusil y Los testigos } \\
\text { 1973: La tierra prometida } \\
\text { 1974: A la sombra del sol } \\
\text { Teleseries } \\
\text { 1968: Amalia } \\
\text { 1969: La chica del bastón } \\
\text { 1970: El padre Gallo }\end{array}$ & \\
\hline
\end{tabular}

Nota: Cine Chile, Bélgica Castro, 2020; Memoria Chilena de la Biblioteca Nacional de Chile, 2020, Alejandro Sieveking (1934-2020). Guiones; Anónimo, 1972; Escuela de Artes Dramáticas, 2007; Cine Chile, Marcelo Gaete, 2019; Rodríguez, 2004. Debido a la fragmentación de la información, esta lista solo se puede considerar como una aproximación. 
Tabla 4. Obras presentadas por Teatro del Ángel en Costa Rica, 1975-1985

\begin{tabular}{ll}
\multicolumn{1}{c}{ Obra } & \multicolumn{1}{c}{ Autor } \\
\hline Corronguísimo & Varios, café concert \\
La virgen del puño cerrado & Alejandro Sieveking \\
Apareció la margarita & Roberto Athayde \\
Gato por liebre & George Feydeau \\
Espectros & Henryk Ibsen \\
Hablemos a calzón quitado & Guillermo Gentile \\
Ja-jaque mate & Varios, café concert \\
Los chinos & Murray Schisgal \\
Los cuernos de don Friolera & Ramón del Valle Inclán \\
La profesión de la señora Warren & Georges Bernard Shaw \\
Toruvio, el ceniciento & Cintolesi-Barahona \\
Cama de batalla & Alejandro Sieveking \\
Pura vida & Varios, café concert \\
El chispero & Alejandro Sieveking \\
El lindo don Diego & Agustín Moreto \\
Pequeños animales abatidos & Alejandro Sieveking \\
La nona & Roberto Cossa \\
Las hermanas de Búfalo Bill & Manuel Martínez Mediero \\
Un, dos, tres & Bertolt Brecht, Terence McNally y Sieveking \\
Tatuajes amorosos en el cuerpo del & Joe Orton
\end{tabular}
difunto

Cien veces no debo

Ricardo Talesnik

La celestina

Fernando de Rojas

Recién chorreado

Varios, café concert

La mula del diablo

Alejandro Sieveking

Bodas de sangre

Federico García Lorca

El hombre elefante

Bernard Pomerance

El médico a palos

Ánimas de día claro

Molière

Orquesta de señoritas

Alejandro Sieveking

Jean Anouilh

Arroz con mango

Varios, café concert

El corazón en la mano

Loleh Bellon

Edipo rey

Sófocles

La dama boba

Lope de Vega

Rosaura a las diez

Marco Denevi

El zoológico de cristal

Cuentos del Decamerón

Tennessee Williams

Giovanni Boccaccio

184 Revista Latinoamericana de Derechos Humanos 
Obra

Esta noche con Lucho

L'anima sola de Chico Muñoz

Nota: (Anónimo, 1985, p.25).
Autor

Jorge Arroyo

\section{Tabla 5. Obras presentadas por Surco en Costa Rica, 1977-1991}

Obra

Sabor a miel

Tú sabes que no te puedo oír cuando el agua está corriendo

La valija

Antropofagia de salón

Querido mentiroso

Comedia a la antigua

A usted le gustan maduras

Sara Benhardt

El inmundo mundo del $\mathrm{M}$.

Buenas noches, mamá

El siguiente

Pareja abierta

La secreta obscenidad de cada día

En casa de Romeo, Julieta de palo

El loco y la triste

Plaza Suite
Autor

Sheila Delaney. Coproducción con el Teatro Universitario. Dirección: Daniel Gallegos. 1976.

Robert Anderson. Dirección: Marcelo Gaete. 1977.

Julio Mauricio. Dirección: Héctor Tealdi. 1977.

Jorge Díaz. Dirección: Marcelo Gaete. 1978.

Jeromy Kilty. Coproducción con el Teatro Arlequín.

Dirección: Lenín Garrido. 1979.

Nicolai Arbuzov. Dirección: Marcelo Gaete. 1982.

Gustavo Campaña, Gloria Moreno y Antonio

Espineira. Coproducción con Teatro La Colina.

Dirección: Marcelo Gaete y Fresia Astica. 1984.

John Murrel. Dirección: Marcelo Gaete. 1986.

Kafka, Chejov, Swift, Durán. Dirección: Marcelo

Gaete. 1987.

Marsha Norman. Coproducción con el Centro

Cultural Costarricense Norteamericano. Dirección:

Marcelo Gaete. 1987.

Terence Mac Neilly. Producción con el Centro

Cultural Costarricense Norteamericano. Dirección: María Bonilla. 1988.

Franca Rame y Darío Fo. Producción del Teatro

Nacional. Dirección: María Bonilla. 1988.

Marco Antonio de la Parra. Dirección: Marcelo Gaete. 1989.

Efraín Kishom. Producción del Teatro Nacional.

Dirección Marcelo Gaete. 1989.

Juan Radrigán. Dirección Marcelo Gaete. 1989.

Neil Simon. Dirección Marcelo Gaete. 1991.

Nota: (Astica, 1991, p. 44). Para una lista que incluya sus actuaciones en obras de otros teatros o coproducciones se recomienda consultar: Castellón, 2007, pp. 121-209. 
Tabla 6. Giras de teatro en Chile, finales de la década de 1980 e inicios de la década de 1990

\begin{tabular}{l|l}
\hline Año & \multicolumn{1}{c}{ Obra } \\
\hline 1987 & El inmundo mundo del m...!, monólogos de Kafka, Chejov y Swift \\
\hline 1987 & Querido mentiroso de Jerome Kilty \\
1988 & Sara Bernhardt de John Murrell \\
\hline 1987 & ¿Puede usted dar saltos mortales? Comedia a la antigua de Alexei Nicolai \\
\hline 1988 & Arbuzov \\
\hline 1988 & El loco y la triste de Juan Radrigán \\
\hline 1990 & Pareja abierta de Franca Rame y Darío Fo \\
\hline 1990 & Big Bang de Samuel Rovinsky \\
\hline 1993 &
\end{tabular}

Nota: Castellón, 2007, pp. 129, 148, 149, 186, 187, 195, 198 y 204.

\section{Referencias}

Anónimo. (1972, marzo). El payasito Bertoldo un amigo de todos los niños. Paula, no. 109, 36. Biblioteca Nacional Digital. http://www.bibliotecanacionaldigital.gob.cl/bnd/628/ w3-article-278094.html

Anónimo. (1974, 1 de diciembre). Cual ave fénix surge desde el exilio y la pasión por el teatro. La Nación, Áncora, 3.

Anónimo. (1977, 27 de noviembre). Teatro del Ángel. "Pura Vida" o la importancia de la risa. La Nación, Áncora, 5.

Anónimo. (1978, 18 de noviembre). Surgen criterios opuestos por subvención a teatros. La Nación, 4A.

Anónimo. (1979, 7 de octubre). Teatro del Ángel: Cuatro años día a día. La Nación, Áncora, 3.

Anónimo. (1980, 18 de diciembre). Se va Teatro del Ángel. La Nación, 6 A.

Anónimo. (1985, 22 al 28 de noviembre). Un teatro con ángel. Rumbo centroamericano, 2(56), 25.

Anónimo. (1988, 17 de noviembre). Alejandro Sieveking. El diario de Aysén, 3. http://www. bibliotecanacionaldigital.gob.cl/bnd/628/w3-article-176768.html

Anónimo. (1995, 1 de febrero). "Islas de porfiado amor" se presenta en Ñuñoa. El Mercurio, C15. http://www.bibliotecanacionaldigital.gob.cl/visor/BND:205342 
Anónimo. (s. f.). Lista para el estreno "La mantis religiosa" en el Teatro del Ángel. http://www. memoriachilena.gob.cl/602/w3-article-86573.html

Archivo de Recursos Humanos (s. f.) Bélgica Castro. UNA.

Astica, S. (1991). Una sala nueva: "La Comedia”. Escena. Revista de las artes, 27(1). https://doi. org/10.15517/es.v0i0.29731

Barahona, L. (2017, 17 de marzo). Comunicación personal. Voces y rostros del exilio chileno en Costa Rica [Oliva, M, coord.]. Proyecto de investigación, IDELA, UNA.

Bermídez, K. (2017, 26 de agosto). El tico como protagonista de telenovelas y teleseries. Revista dominical, (Especial 70 aniversario). https://www.nacion.com/revista-dominical/especial-70-aniversario-el-tico-como-protagonista-de-telenovelas-y-teleseries/ IMUVBWJLJJAP3FXZOKX4DTJGBQ/story/

Bermúdez, M. (1991, marzo). Marcelo Gaete y Sara Astica. Queremos abrirle la comedia al corazón de Costa Rica. Semanario Universidad, Forja, 4.

Bonilla, M. (2009, 27 de marzo). Recordando a tres forjadoras de vida. Semanario Universidad, Forja, 7.

C. H. (1995, 20 de enero). Grupo Surco estrena "Islas de porfiado amor". La época. http://www. bibliotecanacionaldigital.gob.cl/visor/BND:205518

Cañas, A. (1978, 10 de octubre). Pequeños animales abatidos. La Prensa Libre, 7.

Carvajal, R. (1985, 14 de enero). Sieveking estrenará "La comadre Lola”. El Mercurio. http:// www.bibliotecanacionaldigital.gob.cl/bnd/628/w3-article-243178.html

Castedo, E. (1982). El teatro chileno de mediados del siglo XX. Andrés Bello.

Castellón, M. (2007). Trayectoria teatral de un exilio chileno: Grupo Surco [Tesis de maestría. Universidad de Costa Rica].

Castro, B. (1979). El eterno problema: ¿Cómo diablos se hace un repertorio? Escena. Revista de las artes, 2(2). https://doi.org/10.15517/es.v0i0.32566

Cine Chile. (s. f.). Bélgica Castro. http://cinechile.cl/persona/belgica-castro/

Cine Chile. (s. f.). Marcelo Gaete. http://cinechile.cl/persona/marcelo-gaete/

Compañía Nacional de Teatro de Costa Rica. (2011). 40 aniversario, 1971-2011. Imprenta Nacional. 
Cortés, C. y Murillo, M. (1992, mayo). Historia de los Premios Nacionales. Revista Nacional de Cultura. EUNED.

Cuevas, R. (1996). El punto sobre la i. Políticas culturales en Costa Rica (1948-1990). MCJD.

Doménech, R. (2013). El teatro del exilio. Cátedra.

Escuela de Artes Dramáticas. (2007, junio). Teatro para el teatro. Sara Astica Cisterna. Cuadernos de Teatro, $\mathrm{N}^{\circ}$.4. UCR.

Escuela de Artes Dramáticas. (s. f.). Teatro Universitario. http://www.teatro.ucr.ac.cr/ teatrouniversitario

Facultad de Artes de la Universidad de Chile. (s. f.). Historia. http://www.tnch.uchile.cl/historia

Fumero, P. (2016). Infraestructura teatral en el siglo XXI: El caso del "teatro comercial" costarricense (1990-2014). Revista Istmo. 33. http://istmo.denison.edu/n33/articulos/13.html

Gallina, A. (2018). La lucha antidictatorial: Tres escenas del exilio teatral argentino. Exilios, un campo de estudios en expansión. CLACSO. https://www.jstor.org/stable/j.ctvfjd125.7 (

Grandé, C. (1989, 7 de enero). Alejandro Sieveking. La Tercera. http://www.bibliotecanacionaldigital.gob.cl/bnd/628/w3-article-177075.html

Herra, R. (1978, 24 de setiembre). Pequeños animales abatidos. La Nación, 4B.

Hurtado, M. y Piña, J. Teatro de Juan Radrigán (11 obras). CENECA. http://www.memoriachilena. gob.cl/602/w3-article-3492.html\#documentos

Hurtado, M., Edwards, P. y Guilisasti, R. (1989). Historia de la TV en Chile (1958-1973). Documentas, Céneca, Chile. http://www.memoriachilena.gob.cl/602/w3-article-9934.html

Hurtado, M., Vidal, H. y Ochsenius, C. (1982). Teatro chileno de la crisis institucional, 1973-1980. Antología Crítica. University of Minnesota y CENECA.

Juncos, C. (2000, 31 de julio). Nacidos para el teatro. La República, Galería, 2B.

Jurado, O y Morales, J. (2003). Víctor Jara. Te recuerda Chile. Editorial Txalaparta y Lom Ediciones. https://books.google.co.cr/books?id=blUWokxjEF8C\&p$\mathrm{g}=\mathrm{PA} 47 \& \mathrm{dq}=\mathrm{B} \% \mathrm{C} 3 \%$ A9lgica $+\mathrm{Castro} \& \mathrm{hl}=\mathrm{es} \& \mathrm{sa}=\mathrm{X} \& \mathrm{ved}=0 \mathrm{ahUKEwiG7-DJi}-$ d7kAhVCL6wKHaXGDg8Q6AEIJzAA\#v=onepage \&q=B\%C3\%A9lgica\%20 Castro\& $\mathrm{f}=$ false

Loaiza, N. (1976, 3 de octubre). Teatro del Ángel: Una empresa floreciente. La Nación, 6. 
Memoria Chilena de la Biblioteca Nacional de Chile. (2020). Alejandro Sieveking (1934-2020). Cronología. http://www.memoriachilena.gob.cl/602/w3-article-3282.html\#cronologia

Memoria Chilena de la Biblioteca Nacional de Chile. (2020). Alejandro Sieveking (1934-2020). Guiones. http://www.memoriachilena.gob.cl/602/w3-article-92073.html

Memoria Chilena de la Biblioteca Nacional de Chile. (2020). Alejandro Sieveking (1934-2020). Presentación. Recuperado de: http://www.memoriachilena.gob.cl/602/w3-article-3282.html

Memoria Chilena de la Biblioteca Nacional de Chile. (2020). Bélgica Castro (1921-2020) . http:// www.memoriachilena.gob.cl/602/w3-article-91987.html

Morales, C. (1974, 1 de diciembre). "La Celestina”, el gran éxito de Bélgica Castro. La Nación, 41B.

Morrúa, C. (2014, enero-junio). El exilio chileno y el teatro en Costa Rica en la década de 1970: Entrevista a Gastón Gaínza. Temas de Nuestra América. Revista de Estudios Latinoamericanos, 55. EUNA.

Morrúa, C. (2019). Desarrollo y evolución del teatro costarricense en la década de 1970 [Tesis de doctorado, inédita, Facultad de Filosofía y Letras, UNA].

Oliva, C. (2012). La difícil viabilidad de la práctica escénica del exilio. Anales de la literatura española contemporánea, 37(2). https://www.jstor.org/stable/23237385

Piña, A. (2014). Historia del teatro chileno (1940-1990). Taurus. https://books.google.co.cr/books/ about/Historia_del_teatro_en_Chile_1941_1990.html?id=-upECgAAQBAJ\&redir_esc=y

Pradenas, L. (2006). Teatro en Chile. Huellas y trayectorias. Siglo XVI-XX. LOM Ediciones. https:// books.google.co.cr/books? id=yHa93-L4iOQC\& printsec=frontcover\&source=gbs_ge_summary_r\& $\mathrm{rad}=0 \#_{\mathrm{v}}=$ onepage $\& \mathrm{q} \& \mathrm{f}=$ false

Pulgar, L. (1994, 2 de noviembre). "Islas de porfiado amor", un canto a la esperanza. La Tercera http://www.bibliotecanacionaldigital.gob.cl/bnd/628/w3-article-204976.html

Rabell, M. (1978, 11 de setiembre). Pequeños animales abatidos. Jornadas Culturales Allende. El Día, 21. http://criticateatral2021.org/html/resultado_bd.php?ID=4865.

Ramírez, M. (2019). Trazando nuevas rutas: Chilenos exiliados en la educación superior costarricense, 1974-1989. Voces y rostros del exilio chileno en Costa Rica [Oliva, M., coord.]. Proyecto de investigación, IDELA, UNA.

Rodríguez, C. (2004, 3 al 18 de setiembre). Marcelo Gaete. "Nací en el escenario”. Ojo, 18 y 19.

Ruiz, M. (1998). History of Surco, a theatre in exile. Master of Arts, Department of Theatre and Film, University of Kansas. 
Salvatierra, L. (1981, 13 de enero). El Teatro del Ángel. La Nación, 5B.

Sieveking, A. (1980). Próximos estrenos del Teatro de Ángel. Escena. Revista de las artes, 3(1). https://doi.org/10.15517/es.v0i0.32582

Sotomayor, P. (1997, 23 de mayo). Bélgica Castro y Alejandro Sieveking: "Somos mutuamente dependientes". La Segunda, 10. Biblioteca Nacional de Chile. http://www.memoriachilena. gob.cl/archivos2/pdfs/MC0058062.pdf

Sznajder, M y Roniger, L. (2013). La política del destierro y el exilio en América Latina. Fondo de Cultura Económica. 